\title{
(C) OPEN ACCESS \\ Long-term survival in a patient with pulmonary spindle cell carcinoma treated with traditional Chinese medicine
}

\author{
Wenyuan Li, ${ }^{1}$ Maoyan Chen, ${ }^{2}$ Yuanhong Zhao ${ }^{2}$
}

'Department of Breast

Oncology, Tianjin Tumor Hospital, Tianjin, China

${ }^{2}$ Department of Oncology, First

Teaching Hospital of Tianjin University of Traditional Chinese Medicine, Tianjin, China

Correspondence to

Professor Yuanhong Zhao, yuanhongzh98@163.com

Accepted 13 August 2018

A Check for updates

(c) BMJ Publishing Group Limited 2018. Re-use permitted under CC BY-NC. No commercial re-use. See rights and permissions. Published by BMJ.

To cite: LiW, Chen $M$ Zhao Y. BMJ Case Rep Published Online First: [please include Day Month Year]. doi:10.1136/bcr-2018 225989

\section{SUMMARY}

Spindle cell carcinoma (SCC) is a rare pulmonary malignancy, accounting for only $0.2 \%-0.3 \%$ of all lung cancers. Therefore, the prognosis and treatment of pulmonary SCC is unclear. There are only 13 reported cases in literature, only three of which had a survival of more than 11 months. Here we reported a long-term survival of a patient with pulmonary SCC who underwent treatment with traditional Chinese medicine. At the most recent follow-up in July 2018, her survival after diagnosis is 48 months and she continues to do well. To our knowledge, this is the longest survival of late stage SCC with the largest tumour burden.

\section{BACKGROUND}

Spindle cell carcinoma (SCC) is a highly malignant pulmonary sarcomatoid carcinoma. There is no standard treatment for this disease, though chemotherapy, surgery and radiation therapy may be considered. Here we reported a 58-year-old woman diagnosed with pulmonary SCC who prolonged her survival with the treatment of traditional Chinese medicine (TCM) in China. Due to her overall weak state and financial hardships, she had chosen not to receive surgery, chemotherapy or radiotherapy. TCM was the last option for this patient. After drinking Chinese herbal soup, her tumour has not only remained stable, but her general condition has also improved. To date, this is the longest survival with baseline quality of life of pulmonary SCC, reported in literature.

\section{CASE PRESENTATION}

A 58-year-old woman presented with recurrent cough with yellow sputum to a cancer hospital in China in July 2014. Medical history and family history were both negative. Thoracic CT showed a large mass located in her right lung invading the right hilum with ipsilateral mediastinal lymph node enlargement. Pathology from fine-needle aspiration showed pulmonary SCC. Typically, conventional therapies include surgery, chemotherapy and radiotherapy. However, due to her weakened condition and financial hardships, she declined conventional treatment of Western medicine (WM). In October 2014, she reported new symptoms including $38^{\circ} \mathrm{C}$ fever and intermittent haemoptysis to a TCM hospital in another city. Given her financial constraints, TCM was the only option for this patient. Our TCM physician gave her herbal prescription whose core components consisted of Ma-xing-shi-gan (MXSG) decoction. With this herbal treatment, her fevers abated, her cough improved, and she no longer reported haemoptysis. She kept this herbal treatment for 8 months $(150-180 \mathrm{~mL}$ orally twice daily). In July 2015, she reported headaches, dizziness and ataxia. A regular head CT and thoracic CT was conducted, indicating a $15.0 \times 13.5 \times 10.0 \mathrm{~cm}$ irregular pulmonary mass at the level of aortic arch (figure $1 \mathrm{~A}, \mathrm{C}$ ) and low-density lesion in the brainstem. The patient denied further MRI evaluation to verify the brain lesion because of the financial issue. Accordingly, a modified herbal treatment introducing Gastrodiae Rhizoma (GR) and Uncaria Ramulus (UR) (Tianma-gou-teng, abbreviated as GRUR) decoction at the basis of MXSG decoction was prescribed to reduce her headaches and dizziness.

\section{OUTCOME AND FOLLOW-UP}

In April 2017, imaging assessment (figure 1B,D) revealed stable disease without further progression. More surprisingly, the patient continues to maintain a normal reported baseline quality of life. To date, she is still alive 48 months after the initial diagnosis.

\section{DISCUSSION}

Pulmonary SCC is a highly malignant variant of carcinoma with histological properties of both epithelial and mesenchymal tumours. ${ }^{1}$ There is no standard treatment for SCC, though the conventional therapies including surgery, chemotherapy and radiotherapy are commonly used. ${ }^{2}$ Previous case reports showed poor prognosis and rapid progression of SCC. ${ }^{2-4}$ In inoperable cases, platinum-based chemotherapy was selected according to non-small cell carcinoma regimens. Only 3 of 12 patients had a survival of more than 11 months. ${ }^{5}$ One case reported complete remission of SCC with clinical and radiographical evidence of remission at 42 months, which is the longest survival to date. In this case, the CT of the thorax revealed a $3.5 \times 4.5 \times 6.5 \mathrm{~cm}$ hilar mass at the level of aortic arch. The patient had medicated herself with oral germanium sesquioxide after receiving two cycles of chemotherapy followed by radiation. ${ }^{6}$ Although we report 48-month survival with stable disease (rather than complete remission), our patient received TCM as the monotherapy with extended 

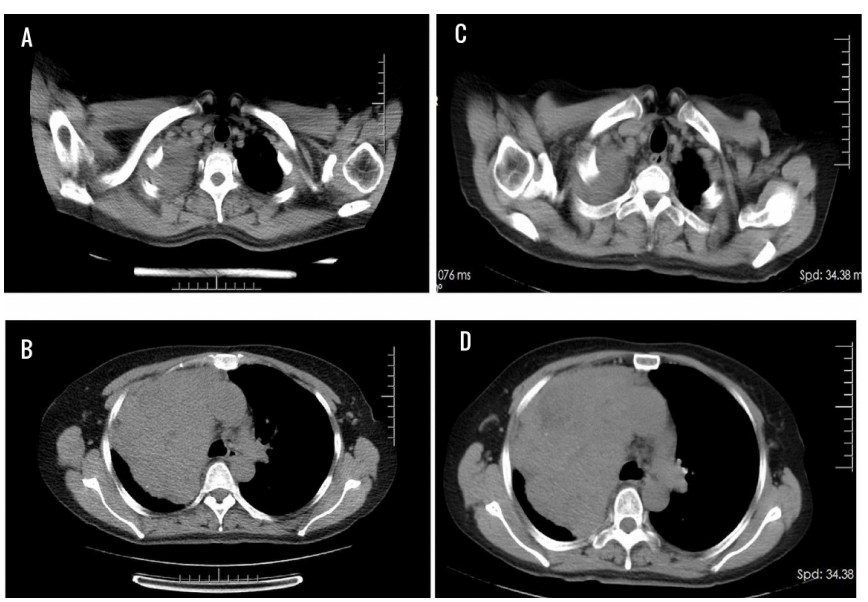

Figure 1 The CT of thorax findings. ( $A$ and C) CT in July 2015 showed an irregular low-density mass from the level of right apex $(A)$ to the level of aortic arch, whose size was $15.0 \times 13.5 \times 10.0 \mathrm{~cm}$. (B and D) CT in April 2017 showed stable disease at the level of apex (B) and aortic arch (D), respectively.

survival and improvement in her quality of life. Of note, it is also the longest survival with the largest pulmonary SCC tumour burden reported in the literature.

TCM has been widely accepted as a complementary medicine for the management of malignancies, particularly as supportive and palliative care of patients with late-stage cancer. ${ }^{7-9}$ Herbal remedies, a major component of TCM, has been used as part of combination therapy or monotherapy to reduce the side effects of chemotherapy. ${ }^{10}$ Due to the complementary role of TCM in western oncology, TCM physicians have primarily treated patients with late-stage disease. Often, the ultimate goals of management at this stage are to prolong the survival and to better the quality of life, rather than to reduce the tumour burden aggressively. Based on TCM theory of fifth elements and yinyang, TCM diagnosis and basal assessment of cancer cannot be fully interpreted in the setting of standard WM system. As this patient declined thorough imaging evaluation with the occurrence of neurological symptoms, it is unclear whether the brain metastases existed or the symptoms resulted from a potential cerebrovascular event. In contrast, per TCM theory, the logical selection of comprehensive herbal formula in each process of disease was made based on 'syndrome differentiation' rather than aetiology of symptoms. ${ }^{11}$ The initial herbal prescription is composed of mostly MXSG decoction, which includes Ephedrae Herba (EH), Semen Armeniacae Amarum (SAA), Gypsum Fibrosum (GF) and Glycyrrhizae Radix et Rhizoma (GR). MXSG decoction has mainly been used to treat cough, bronchial inflammation and fever from bacterial pneumonia or viral infection in China. ${ }^{12-14}$ Among these components, EH and SAA have been individually shown to have anti-inflammatory and immunomodulatory effects on the respiratory system. ${ }^{15-17}$ The subsequent treatment, which introduced GR and UR, is indicated for neurodegenerative disease in China. ${ }^{18-20}$ Aside from these core components, TCM physicians also added other adjuvant components to enhance the function of core components for this patient. Of note, two components, Hedyotis Diffusa (HD) and Scutellaria Baicalensis (SB), have demonstrated antitumour effects in various types of cancer, including colorectal cancer, ${ }^{21} 22$ ovarian cancer, ${ }^{23} 24$ pancreatic cancer ${ }^{25}$ and lung cancer. ${ }^{26-28}$ However, there are few studies of these decoctions, as a combination, in the realm of cancer management. Regardless, the TCM regimen helped to improve her symptoms and halt progression of disease.

Clinically and radiographically, our patient has experienced stable disease since undergoing treatment with herbal therapy, a period of 36 months. However, the precise underlying mechanism is unclear. There is increasing evidence that TCM may have a special role in improving the quality of life and potentially prolonging survival of patients with malignancy. ${ }^{9} 2930$ There remains a need to investigate the potential roles of complementary medicine in the treatment and survival of patients with cancer.

\section{Learning points}

- We reported a long-term survival of a patient with pulmonary spindle cell carcinoma (SCC) who underwent treatment with traditional Chinese medicine (TCM) as the monotherapy. Of note, it is the longest survival with largest pulmonary SCC tumour burden reported in the literature.

- Due to its complementary role in mainstream oncology, TCM may be the last option for patients with late stage disease, which often means that the ultimate goal of management is to prolong survival and to better the quality of life.

- Based on theoretical differences between Western medicine (WM) and TCM, the choice of herbal prescription cannot be easily understood in the context of modern WM. Yet, the clinical efficacy and potential role of TCM in late-stage malignancy should not be ignored.

Acknowledgements We thank Lucy Liu for providing assistance with editing the final manuscript.

Contributors WL summarised the case presentation and completed the manuscript. MC collected the patient's information and clinical data. YZ prescribed the patient with TCM therapy and provided all the TCM theory support.

Funding The authors have not declared a specific grant for this research from any funding agency in the public, commercial or not-for-profit sectors.

Competing interests None declared.

Patient consent Obtained.

Provenance and peer review Not commissioned; externally peer reviewed.

Open access This is an open access article distributed in accordance with the Creative Commons Attribution Non Commercial (CC BY-NC 4.0) license, which permits others to distribute, remix, adapt, build upon this work non-commercially, and license their derivative works on different terms, provided the original work is properly cited and the use is non-commercial. See: http://creativecommons.org/ licenses/by-nc/4.0/

\section{REFERENCES}

1 Gupta R, Singh S, Hedau S, et al. Spindle cell carcinoma of head and neck: an immunohistochemical and molecular approach to its pathogenesis. J Clin Pathol 2007;60:472-5.

2 Feng L, Cai D, Muhetaer A, et al. Spindle cell carcinoma: the general demographics, basic clinico-pathologic characteristics, treatment, outcome and prognostic factors. Oncotarget 2017;8:43228-36.

3 Kida J, Kanaji N, Kishi S, et al. An autopsy case of rapidly progressing spindle cell carcinoma of the lung accompanied with intratumor hemorrhage. Am J Case Rep 2015; 16:805-10

4 Qi DJ, Liu B, Feng L, et al. Pulmonary spindle cell carcinoma with unusual morphology: a rare case report and review of the literature. Medicine 2017;96:e7129.

5 Tonai K, Kitasato Y, Kawakami T, et al. [Autopsy case of rapidly progressive pulmonary spindle cell carcinoma with multiple metastases to the brain and pancreas]. Nihon Kokyuki Gakkai Zasshi 2009;47:828-32.

6 Mainwaring MG, Poor C, Zander DS, et al. Complete remission of pulmonary spindle cell carcinoma after treatment with oral germanium sesquioxide. Chest 2000;117:591-3. 
7 Nahin RL, Barnes PM, Stussman BJ, et al. Costs of complementary and alternative medicine (CAM) and frequency of visits to CAM practitioners: United States, 2007. Natl Health Stat Report 2009;18:1-14.

8 Xu J, Song Z, Guo Q, et al. Synergistic effect and molecular mechanisms of traditional chinese medicine on regulating tumor microenvironment and cancer cells. Biomed Res Int 2016;2016:1-14.

9 Konkimalla VB, Efferth T. Evidence-based Chinese medicine for cancer therapy. J Ethnopharmacol 2008;116:207-10.

10 Ye L, Jia Y, Ji KE, et al. Traditional Chinese medicine in the prevention and treatment of cancer and cancer metastasis. Oncol Lett 2015;10:1240-50.

11 Dong J. The relationship between traditional Chinese medicine and modern medicine. Evid Based Complement Alternat Med 2013;2013:1-10.

12 Liao YN, Hu WL, Chen HJ, et al. The use of Chinese herbal medicine in the treatment of Chronic Obstructive Pulmonary Disease (COPD). Am J Chin Med 2017;45:225-38.

13 Lin YC, Chang CW, Wu CR. Antitussive, anti-pyretic and toxicological evaluation of Ma-Xing-Gan-Shi-Tang in rodents. BMC Complement Altern Med 2016;16:622.

14 Ma LQ, Pan CS, Yang N, et al. Posttreatment with Ma-Xing-Shi-Gan-Tang, a Chinese medicine formula, ameliorates lipopolysaccharide-induced lung microvessel hyperpermeability and inflammatory reaction in rat. Microcirculation 2014;21:649-63.

15 Aoki K, Yamakuni T, Yoshida M, et al. Ephedorae herba decreases lipopolysaccharideinduced cyclooxgenase-2 protein expression and NF-kappaB-dependent transcription in C6 rat glioma cells. J Pharmacol Sci 2005;98:327-30.

16 Lam P, Cheung F, Tan HY, et al. Hepatoprotective effects of chinese medicinal herbs: A Focus on Anti-Inflammatory and Anti-Oxidative Activities. Int J Mol Sci 2016;17:465.

17 Yue GG, Chan BC, Kwok HF, et al. Screening for anti-inflammatory and bronchorelaxant activities of 12 commonly used Chinese herbal medicines. Phytother Res 2012;26:915-25.

18 Xian JW, Choi AY, Lau CB, et al. Gastrodia and Uncaria (tianma gouteng) water extract exerts antioxidative and antiapoptotic effects against cerebral ischemia in vitro and in vivo. Chin Med 2016;11:27

19 Chik SC, Or TC, Luo D, et al. Pharmacological effects of active compounds on neurodegenerative disease with gastrodia and uncaria decoction, a commonly used poststroke decoction. ScientificWorldJournal 2013;2013:1-22.
20 Huan T, Xian JW, Leung WN, et al. Cerebrospinal fluid metabolomics after natural product treatment in an experimental model of cerebral ischemia. OMICS 2016;20:670-80

21 Feng J, Jin Y, Peng J, et al. Hedyotis diffusa willd extract suppresses colorectal cancer growth through multiple cellular pathways. Oncol Lett 2017;14.

22 Liu X, Wu J, Zhang D, et al. A network pharmacology approach to uncover the multiple mechanisms of hedyotis diffusa willd. on colorectal cancer. Evid Based Complement Alternat Med 2018;2018:1-12.

23 Yan $\mathrm{H}$, Xin $\mathrm{S}$, Wang $\mathrm{H}$, et al. Baicalein inhibits MMP-2 expression in human ovarian cancer cells by suppressing the $\mathrm{p} 38$ MAPK-dependent NF- $\mathrm{\kappa B}$ signaling pathway. Anticancer Drugs 2015:1.

24 Gao C, Zhou Y, Li H, et al. Antitumor effects of baicalin on ovarian cancer cells through induction of cell apoptosis and inhibition of cell migration in vitro. Mol Med Rep 2017;16:8729-34.

25 Zhou RT, He M, Yu Z, et al. Baicalein inhibits pancreatic cancer cell proliferation and invasion via suppression of NEDD9 expression and its downstream Akt and ERK signaling pathways. Oncotarget 2017;8.

26 You J, Cheng J, Yu B, et al. Baicalin, a chinese herbal medicine, inhibits the proliferation and migration of human non-small cell lung carcinoma (NSCLC) Cells, A549 and H1299, by Activating the SIRT1/AMPK signaling pathway. Med Sci Monit 2018;24:2126-33.

27 Kim HJ, Park C, Han MH, et al. Baicalein induces caspase-dependent apoptosis associated with the generation of ROS and the activation of AMPK in human lung carcinoma A549 cells. Drug Dev Res 2016;77:73-86.

28 Zheng F, Wu J, Zhao S, et al. Baicalein increases the expression and reciprocal interplay of RUNX3 and FOXO3a through crosstalk of AMPK $\alpha$ and MEK/ERK1/2 signaling pathways in human non-small cell lung cancer cells. J Exp Clin Canc Res 2015:34:11.

29 Wu CT, Lai JN, Tsai YT. The prescription pattern of Chinese herbal products that contain dang-qui and risk of endometrial cancer among tamoxifen-treated female breast cancer survivors in Taiwan: a population-based study. PLoS One 2014:9:e113887.

$30 \mathrm{Hu}$ B, Wang SS, Du Q. Traditional Chinese medicine for prevention and treatment of hepatocarcinoma: From bench to bedside. World J Hepatol 2015;7:1209-32.

Copyright 2018 BMJ Publishing Group. All rights reserved. For permission to reuse any of this content visit http://group.bmj.com/group/rights-licensing/permissions.

BMJ Case Report Fellows may re-use this article for personal use and teaching without any further permission.

Become a Fellow of BMJ Case Reports today and you can:

- Submit as many cases as you like

- Enjoy fast sympathetic peer review and rapid publication of accepted articles

- Access all the published articles

- Re-use any of the published material for personal use and teaching without further permission

For information on Institutional Fellowships contact consortiasales@bmjgroup.com

Visit casereports.bmj.com for more articles like this and to become a Fellow 